\title{
Brain stones revisited-between a rock and a hard place
}

\author{
Froilan G. Celzo • Caroline Venstermans • Frank De Belder • \\ Johan Van Goethem • Luc van den Hauwe • Thijs van der Zijden • \\ Maurits Voormolen • Tomas Menovsky • Andrew Maas • Paul M. Parizel
}

Received: 4 July 2013 / Accepted: 31 July 2013 /Published online: 11 September 2013

(C) The Author(s) 2013. This article is published with open access at Springerlink.com

\begin{abstract}
Objectives and methods Large intracranial calcifications are occasionally encountered in routine computed tomography (CT) scans of the brain. These calcifications, also known as "brain stones", can be classified according to location and aetiology. Combining imaging findings with relevant clinical history and physical examination can help narrow down the differential diagnosis and may allow confident diagnosis in certain situations.

Results This article provides a pictorial review illustrating various clinical entities resulting in brain stones.

Discussion Based on location, brain stones can be classified as extra- or intra-axial. Extra-axial brain stones comprise tumours and exaggerated physiological calcifications. Intraaxial brain stones can further be classified according to aetiology, namely neoplastic, vascular, infectious, congenital and endocrine/metabolic. Imaging findings combined with essential clinical information can help in narrowing the differential diagnosis, determining disease state and evaluating effect of therapy.

Teaching Points

- Based on location, brain stones can be either extra- or intraaxial.

- Extra-axial brain stones comprise tumours and exaggerated physiological calcifications.

- Intra-axial aetiologies include neoplastic, vascular, infectious, congenital and endocrine/metabolic.
\end{abstract}

F. G. Celzo $(\square) \cdot$ C. Venstermans $\cdot$ F. De Belder · J. Van Goethem • L. van den Hauwe • T. van der Zijden • M. Voormolen • P. M. Parizel Department of Radiology, Antwerp University Hospital, University of Antwerp, Wilrijkstraat 10, 2650 Edegem, Belgium e-mail: froicelzo@gmail.com

T. Menovsky $\cdot$ A. Maas

Department of Neurosurgery, Antwerp University Hospital, University of Antwerp, Wilrijkstraat 10, 2650 Edegem, Belgium
- CT scan is the mainstay in identifying and characterising brain stones.

- Certain MRI sequences (gradient echo T2* and susceptibilityweighted imaging) are considered adjunctive.

Keywords Brain diseases/pathology* . Calculi* .

Calcinosis $\cdot$ Computed tomography $\cdot$ Diagnosis $\cdot$ Differential

\section{Introduction}

Brain stones or cerebral calculi are defined as large solid intracranial calcifications [1,2]. These lesions were once thought to be rare and were mostly seen in patients with seizures $[1,2]$. Intracerebral haematomas, tuberculomas and brain abscesses were postulated to be the most common underlying pathologies leading to the development of these intracranial calcifications [2, 3]. The introduction of crosssectional imaging modalities, particularly computed tomography (CT), has allowed easier identification of intracerebral calcifications and specifically the lesser common brain stones in a wide range of clinical entities and disease states [4]. This article provides a pictorial review illustrating various clinical entities resulting in brain stones (Table 1).

\section{Definition}

Tiberin [1] defined "brain stones" or "cerebral calculi" as general terms referring to "large, solitary or multiple, wellcircumscribed bony hard areas of pathological intracerebral calcification", the aetiopathologies of which were thought to be the end result of chronic, insidious "non-neoplastic spaceoccupying lesions". The lack of specific data regarding the amount and configuration of calcium salts that would allow detection by plain $\mathrm{x}$-ray is compounded by the fact that no consensus exists on how histological characteristics of intracranial calcifications explain the appearance of intracranial 
Table 1 Classification of brain stones according to location and aetiopathology

\begin{tabular}{lc}
\hline Location/aetiology & Examples \\
\hline Extra-axial & $\begin{array}{c}\text { Meningiomas, dural osteomas, calcifying } \\
\text { tumours (e.g., craniopharyngiomas), } \\
\text { calcifying pseudoneoplasms of the } \\
\text { neuraxis (CAPNON), exaggerated } \\
\text { physiological calcifications }\end{array}$ \\
& \\
Intra-axial & Oligodendrogliomas, medulloblastoma, germ \\
Neoplastic & cell tumours, primitive neuroectodermal \\
& tumours (PNET), dysembryonic \\
& neuroectodermal tumours (DNET), \\
& gangliomas, pilocytic astrocytomas \\
& Cavernous malformations, arteriovenous \\
& malformations, dystrophic calcification \\
in chronic infarction, chronic vasculitis, & aneurysms \\
Vascular & TORCH (toxoplasmosis, rubella, \\
& cytomegalovirus, herpes simplex), \\
tuberculosis, parasitic infections \\
(e.g. neurocyticercosis, cerebral \\
hydatid cyst disease) \\
Sturge-Weber syndrome, tuberous sclerosis, \\
lipomas, neurofibromatosis \\
Fahr's syndrome, hypoparathyroidism, \\
pseudohypoparathyroidism, \\
hyperparathyroidism \\
\hline Endocrine/metabolic
\end{tabular}

calcifications on plain $\mathrm{x}$-rays $[3,5,6]$. Similarly, there is no clear cutoff value as to what "large" pertains to in the definition of brain stones. The superiority of $\mathrm{CT}$ in detecting macroscopic intracranial calcifications as compared to plain $\mathrm{x}$-rays has resulted in routine visualisation of various forms and sizes of intracranial calcification [7]. Despite the ability of CT to quantify calcification, the subjective designation of intracranial calcifications as brain stones has been considered of less importance lately, although the challenge of reaching a radiological diagnosis on the basis of their presence has remained an intellectual curiosity [2].

\section{Imaging modalities}

In a historical context, conventional skull x-rays have been most instrumental in identifying brain stones. The use of various projections has helped localise brain stones and, in some instances, narrow the differential diagnosis $[6,8,9]$. The introduction of the Potter-Bucky grid in the 1920s further increased the detection rate of skull x-rays [5]. CT (and especially the multidetector CTs), because of their multiplanar reconstruction (MPR) and 3D reconstruction capabilities, have supplanted the use of skull $\mathrm{x}$-rays in the diagnosis of intracranial pathology. They are also considered to be better than magnetic resonance imaging (MRI) in identifying and characterising intracranial
Fig. 1 A 59-year-old female with back pain and an abnormal bone scan that showed a focal lesion in the skull. The faint calcification seen at the lateral skull $\mathrm{x}$-ray (a) was confirmed on non-contrastenhanced CT (NCECT) to be a calcified meningioma overlying the right frontal cortex (b), better visualised on the 3D reconstruction (c). Note the displacement of adjacent brain parenchyma ("cortical buckling"), which strongly suggests the extra-axial location of this lesion
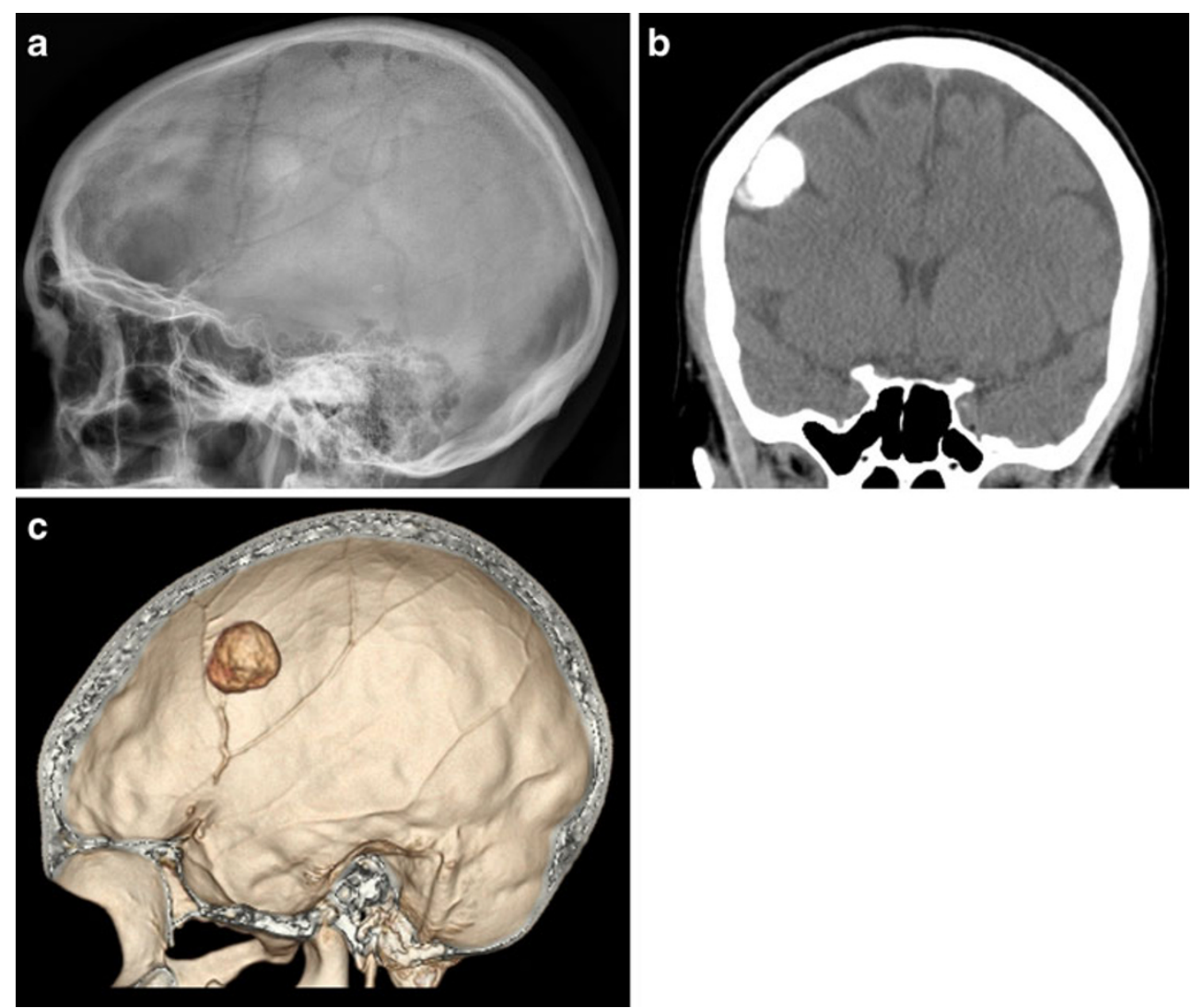
calcification [4, 10], although newer MRI sequences such as gradient echo $\mathrm{T} 2 *$ and susceptibility-weighted imaging have been shown to be promising in detecting intracranial calcification [11-13]. In certain clinical situations, neurological symptoms have even been shown to correlate better with MRI findings than with the corresponding CT-identified calcifications [14-16].

\section{Classification of brain stones}

As with many other intracranial pathologies, brain stones can be localised and classified as either extra- or intra-axial. Various imaging findings have been found to suggest an extra-axial localisation of brain lesions such as buckling of adjacent white matter, expansion of the ipsilateral subarachnoid space, presence of bony reactions and the "dural tail" sign [17].

\section{Extra-axial}

The most common extra-axial aetiologies of brain stones include meningiomas, dural osteomas, calcifying tumours (e.g. craniopharyngiomas) as well as exaggerated physiological calcifications [5, 8, 18]. Macroscopic calcifications are present in meningiomas in up to $60 \%$ of cases, the pattern of which may range from diffuse, rim or sand-like to focal or even globular (Fig. 1) $[8,18,19]$. Calcified meningiomas can be associated with focal thickening of the overlying skull bones or with dilatation of the adjacent air-containing sinus
Fig. 2 Dural osteoma. A 53year-old female who presented with a headache and distant history of head trauma. The FLAIR (a) and MIP-SWI (b) MRI sequences showed an area of signal loss (white arrows) in the right temporal lobe initially thought to represent an enlarged post-traumatic air cell.

Subsequent NCECT (c) and 3D reconstruction (d) revealed a solid calcified lesion (black arrow) adherent to the squamous part of the temporal bone. Note the cortical buckling (a), which suggests an extra-axial location. The homogeneously solid calcification (c) suggests a dural osteoma instead of a dural ossification
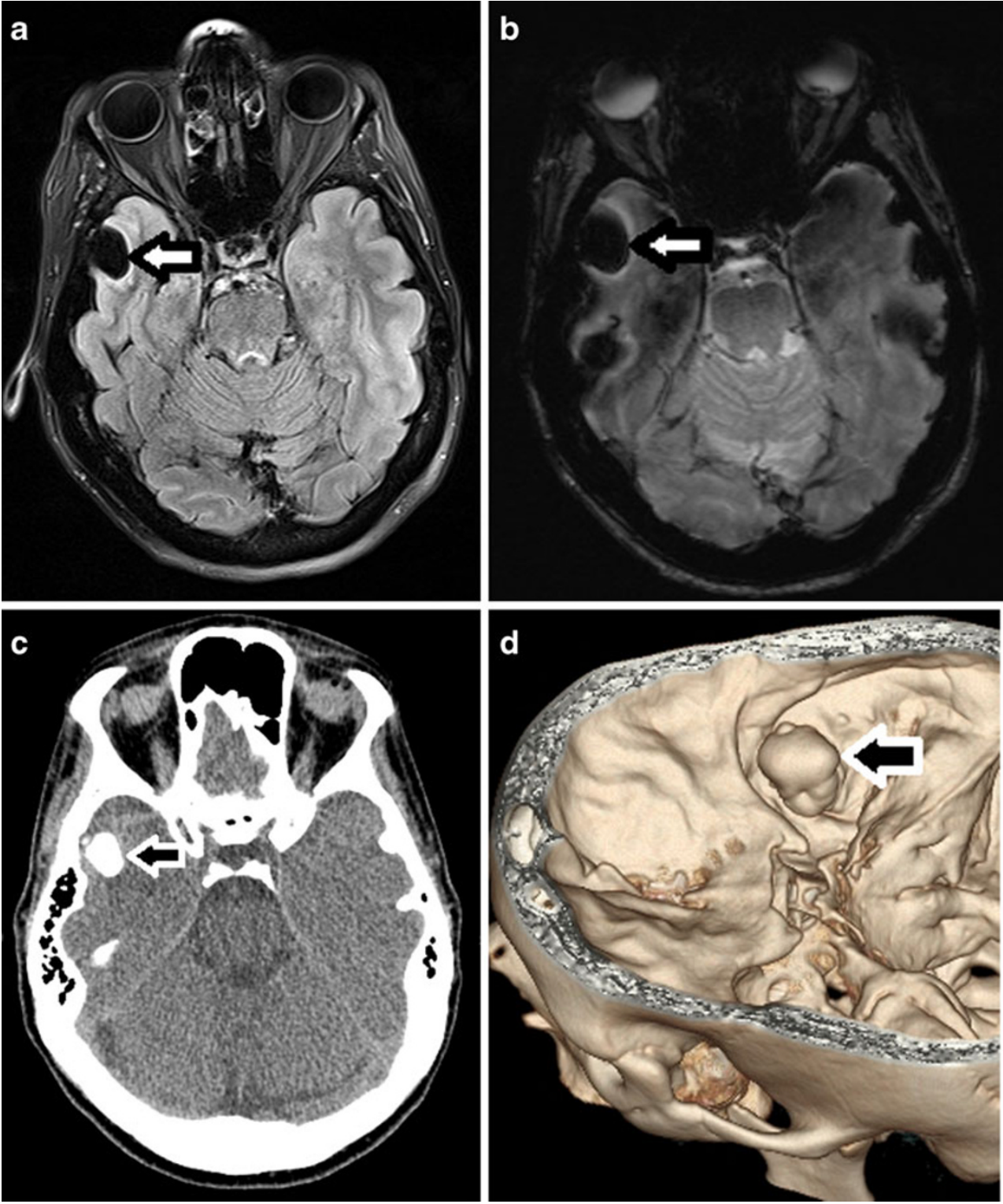
of the skull base [20]. Dural osteomas are believed to be a result of new bone formation arising from the dura and falx; conversely, intra-axial intracerebral osteomas are postulated to originate from primitive mesenchymal cells that have migrated from connective tissue (Fig. 2). Unique to these rare ossified tumours is the fact that they do not possess a laminated bony architecture, but present as a solid mass of calcification $[21,22]$. Craniopharyngiomas are frequently located in the suprasellar region and usually present with haemorrhage and calcification mainly in an amorphous and sometimes lobulated pattern $[8,23]$. Calcifying pseudoneoplasms of the neuraxis (CAPNON) are extremely rare fibro-osseous lesions that can be extra- or intra-axial. Histologically, these benign lesions are composed of a pathognomonic chondromyxoid matrix in an amorphous or nodular pattern as well as palisading spindle or epithelioid cells and varying proportions of fibrous stroma [24-26]. When present in the skull base, they are known to symptomatically encase cranial nerves. Lastly, exaggerated physiological calcifications can theoretically lead to identification of brain stones in radiological examinations. Structures known to calcify include the pineal gland, choroid plexus, habenula, dura and arachnoid, falx cerebri, tentorium cerebelli, superior sagittal sinus, petroclinoid and interclinoid ligaments, arachnoid granulations and intra-axially the basal ganglia and cerebellum [9, 27]. Although physiological calcifications are usually considered of no clinical significance, the presence of pathology may be suspected in cases of abnormal increase in their usual size [e.g. normal choroid plexus calcification versus a choroid papilloma (Fig. 3) or carcinoma], location (e.g. displaced pineal gland due to tumour) or age at presentation [e.g. age-related basal ganglia calcification versus Fahr's disease in younger individuals (Fig. 9)] $[8,18,19]$.

Dural calcifications and ossifications, especially of the falx cerebri, can also appear as "brain stones". They generally do not have any clinical significance and are often incidental findings during CT scans of the brain [28]. Dural calcifications, which are a result of calcium salt deposition, should not
Fig. 3 A 17-year-old female with seizures presented with a large calcified mass apparently arising from the left temporal lobe. The calcification pattern (mostly peripheral) and morphology ("popcorn appearance") strongly suggested a vascular lesion such as a cavernous malformation (cavernous angioma) or, less likely, a calcified haemangioma. Upon excision, the mass was later found to be a choroid plexus papilloma, shown in the axial NCECT in soft tissue (a) and bone windows (b) as well as the coronal NCECT reconstruction in soft tissue (c) and bone windows (d)
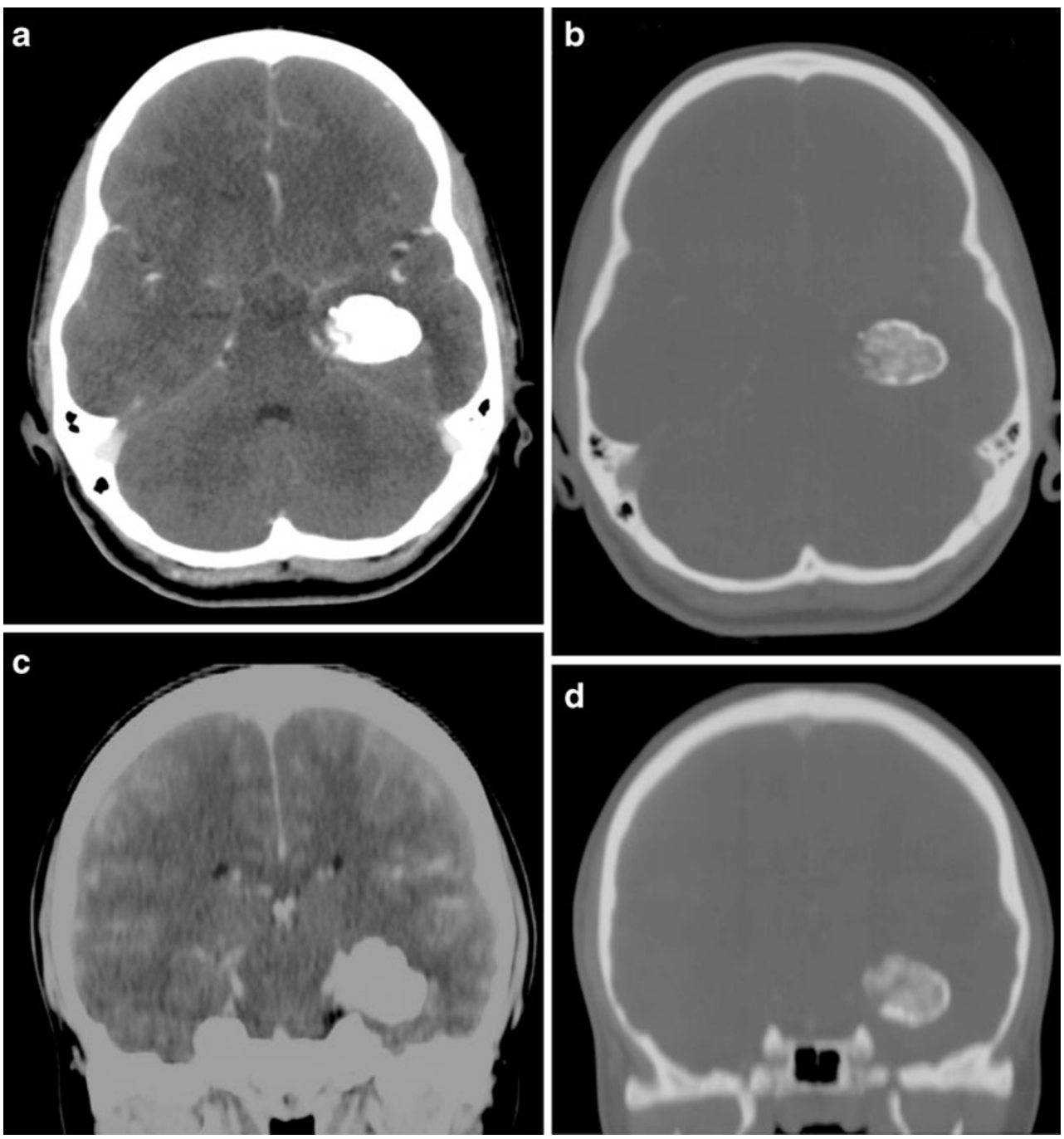
be confused with dural ossifications, which actually involves new bone formation [29]. As the falx is derived from multipotential mesenchymal cells, they may become osteogenic after exposure to friction, haemorrhage or trauma [29, 30]. Ossifications in the falx cerebri are considered to be a rare phenomenon [9, 31, 32]. However, their incidence may be underestimated as it has been shown that a percentage of previously identified dense calcification on conventional radiography and CT may actually possess an outer shell of cortical bone surrounding an inner core of (fatty) bone marrow using modern high-resolution CT and MR imaging [28, 31, 32]. They can range in size from small islands of bone to large bony structures, can involve the entire falx $[29,33]$ and can be associated with certain endocrine and congenital disorders $[30,33]$.

\section{Intra-axial}

Intra-axial aetiologies of calcifications potentially resulting in formation of brain stones comprise a broad range of pathologies that can be subdivided into neoplastic, vascular, infectious, congenital and endocrine/metabolic [2, 8, 18, 34].

\section{Neoplastic}

Various intracranial tumours are associated with haemorrhage because of a combination of neovascularisation, intralesional arteriovenous shunt formation and rapid enlargement that outgrows the tumour blood supply resulting in necrosis, especially in those with high tumour grades. This condition then promotes disruption of intracellular calcium regulation, resulting in calcium deposition $[23,34,35]$. Tumours most likely to calcify and form brain stones include the slow-growing oligodendrogliomas, in which up to $90 \%$ are known to calcify, resulting in typical dense clump-like calcifications (Fig. 4) [18, 23]. In some cases, the calcification can be punctate, ribbonlike or even peripherally located, and can extend into adjacent brain parenchyma. Low-grade astrocytomas are by far the most common glial neoplasms. However, only a small fraction of these tumours are known to calcify, with patterns ranging from linear, diffuse to punctate. Medulloblastomas are also known to calcify in about $10-20 \%$ of cases [36]. Other brain tumours may calcify to various degrees such as pineal gland tumours, germ cell tumours, primitive neuroectodermal tumours (PNET), dysembryonic neuroectodermal tumours (DNET), gangliogliomas and pilocytic astrocytomas. Although rare, metastasic tumours to the brain can also calcify, often in the setting of treatment [37]. Combined with other imaging features, the presence, but not the pattern of calcification can narrow down the differential diagnosis of intracranial neoplasms. In the same context, the presence of calcification in tumours is not associated with the pathological grade of malignancy, but the eventual development thereof may suggest a favourable response to therapy $[5,38]$.
Fig. 4 A 68-year-old male with transient right-sided hemiparesis. This preoperative NCECT was done following discovery of suspicious lesions from a recent MRI (not available). Axial (a), sagittal (b) and 3D reconstruction (c) show a calcified lesion (black arrows) in the left post central gyrus. The entire lesion was surgically removed and was found to be a glioblastoma with an extensive oligodendroglioma component. Ninety percent of oligodendrogliomas are known to form dense, clump-like calcifications
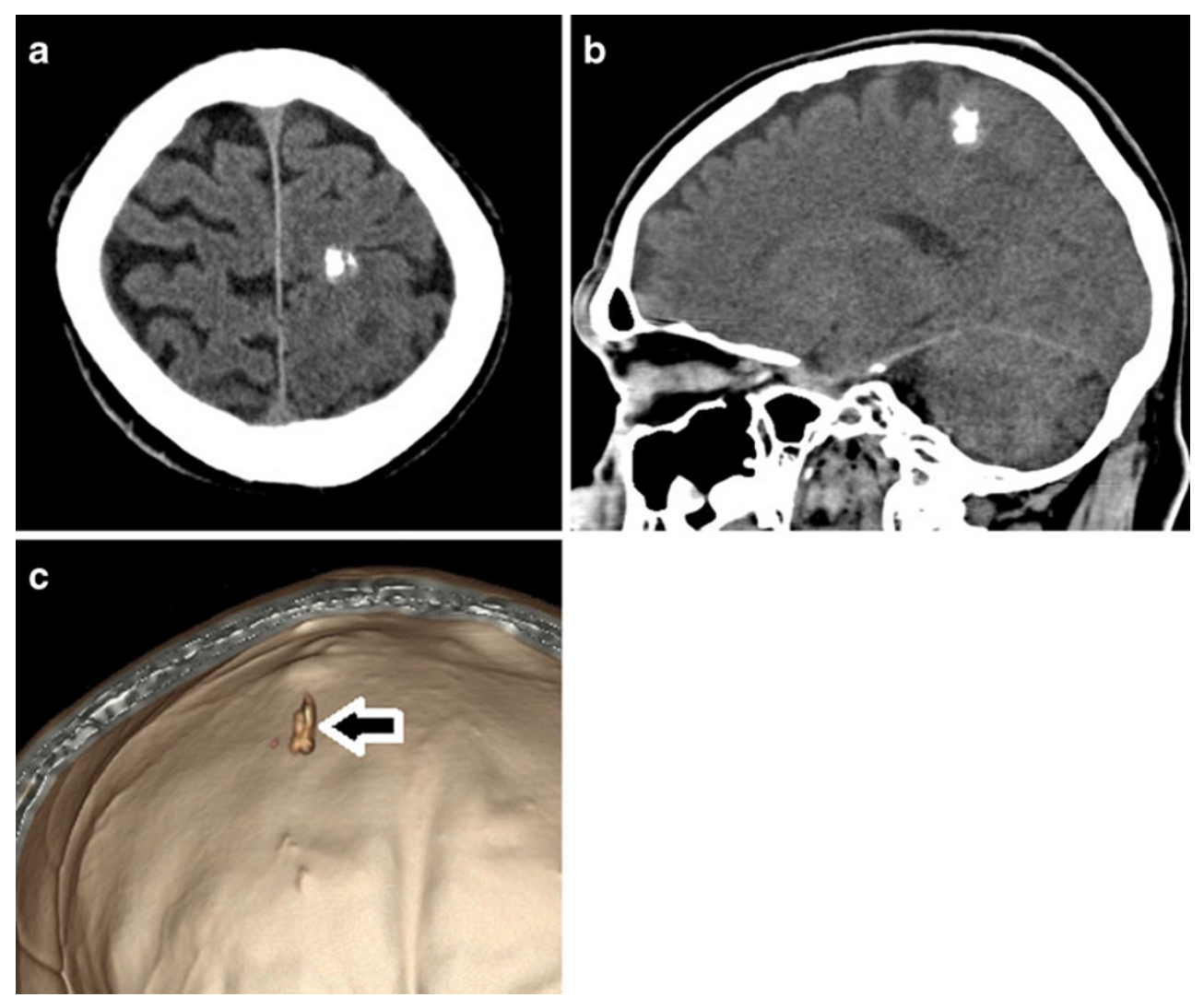
Fig. 5 Dystrophic calcification in a 73-year-old female with a prior history of intracranial bleed who presented with loss of consciousness. The NCECT scan (a), close-up view (b) and 3D reconstruction (c) showed "brain stones" (black arrows) in the middle of the pathological brain regions. There is also an intraventricular drain present (white arrows). The subsequent appearance of calcifications in known post-traumatic or postischaemic areas of the brain is largely attributed to dystrophic calcification
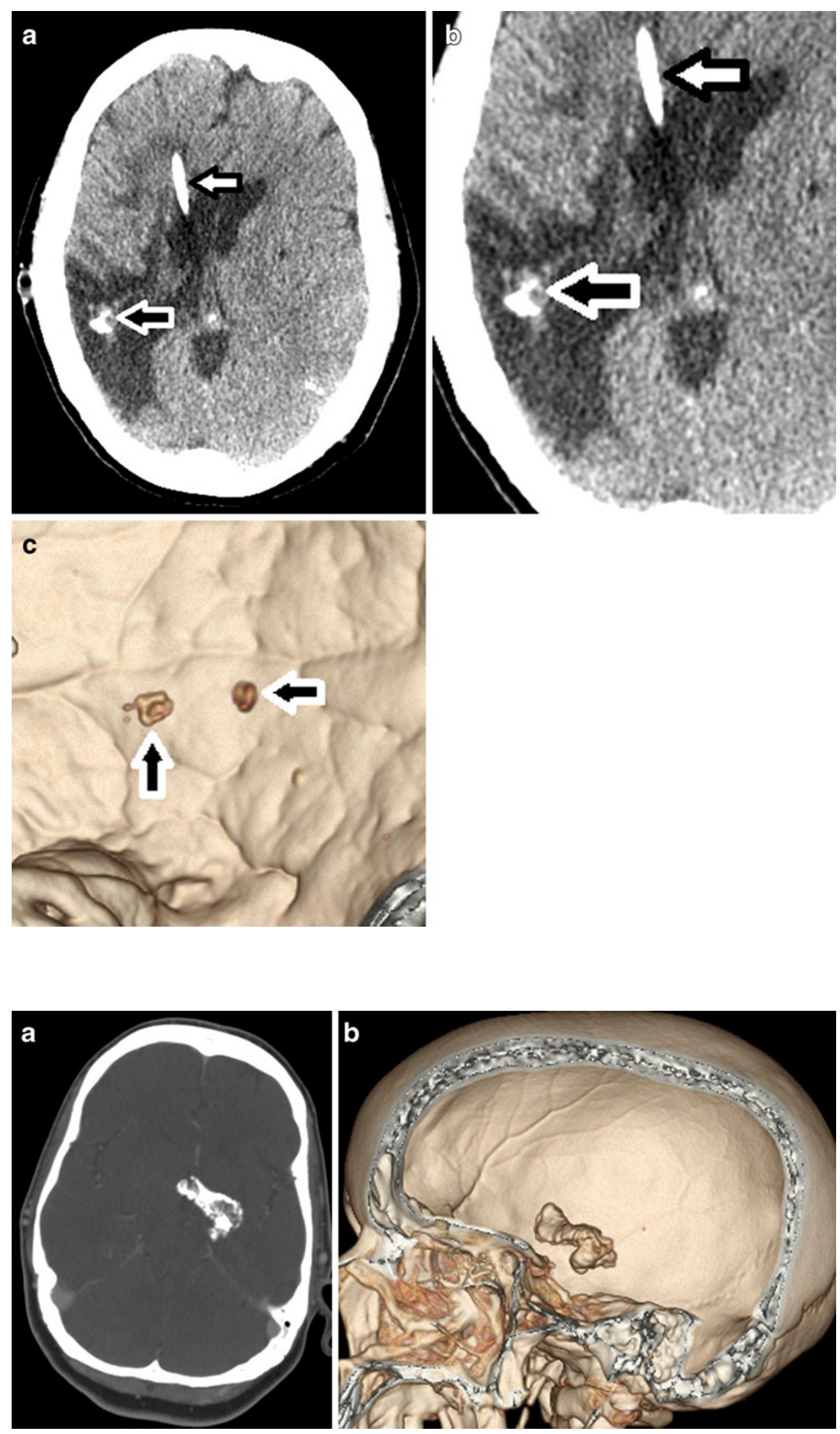

Fig. 6 Axial CT in bone windows (a) and 3D

reconstruction (b) of a 33-yearold male with temporal lobe epilepsy. The large amorphous calcification seen at the base of the left temporal lobe in this NCECT represents a known case of an embolised AV

malformation. Calcifications are known to appear in 25-30\% of cases in close conjuction with serpentine vessels or within adjacent brain parenchyma 


\section{Vascular}

Ever since Shafey first reported brain stones due to angiomatous (cavernous) malformations, vascular pathologies have been recognised as important causes of intracranial calcification in general [2]. Other vascular lesions that may result in the formation of intracranial calcifications and brain stones include arteriovenous malformations, dystrophic calcification in chronic infarction, chronic vasculitis and aneurysms (Fig. 5) [39]. In most situations, radiological features as well as location allow differentiation between these entities. Pathophysiological mechanisms leading to cal- cification include chronic venous ischaemia and the formation of dystrophic calcification as a result of haemorrhage. Calcification in arteriovenous malformations (AVM) is seen in about $25-30 \%$ of cases, mostly along the serpentine vessels, in adjacent brain parenchyma or within the nidus (Fig. 6). The incidence of calcification in cavernous malformations is higher, estimated to be around 40-60\% of cases, often with the typical "popcorn-ball" appearance [40]. Vasculitis leading to microinfarctions and subsequent dystrophic calcifications can be seen in a number of pathologies, such as in systemic lupus erythematosus [41]. The presence of a round or lobulated densely calcified mass in the suprasellar or parasellar
Fig. 7 A 60-year-old male known HIV patient presented with seizures. The solid calcifications on NCECT at the right frontal (a) left basal ganglia (b) and right parietal areas (c) represent sequela following treatment for documented toxoplasmosis. 3D reconstruction (d). In congenital toxoplasmosis, calcifications have been shown to decrease in size or even completely resolve with treatment
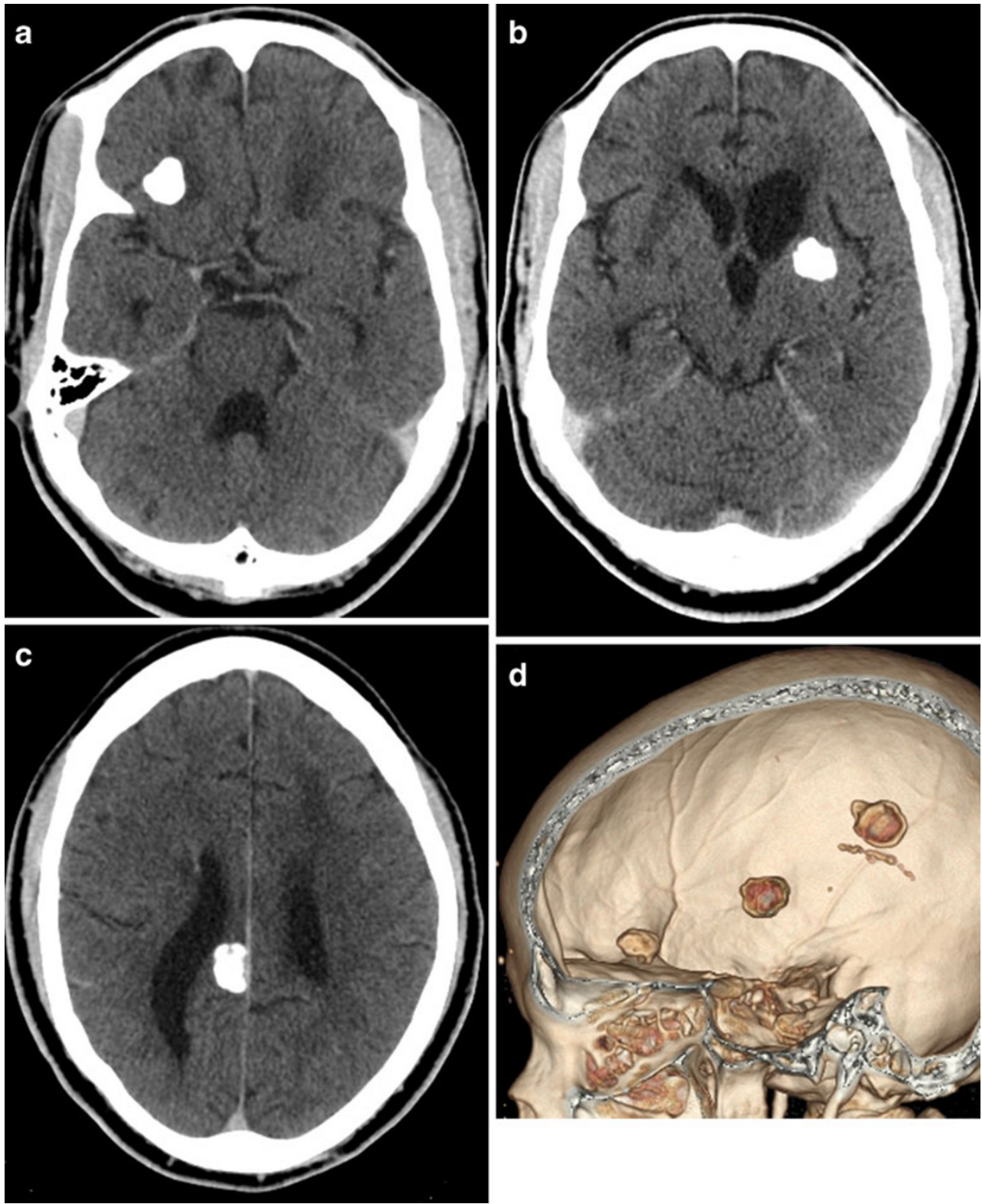
regions is highly suggestive of the presence of a calcified brain aneurysm. The calcification in this case involves the vessel wall, usually in larger aneurysms, and their presence can correlate with the extent of intraluminal thrombosis [42].

\section{Infectious}

Central nervous system infections leading to intracranial calcification are most often seen in congenital childhood infections, particularly the "TORCH" group, which includes toxoplasmosis, rubella, cytomegalovirus and herpes simplex infections. As with vascular pathologies, the mechanism of calcification involved in these infections is dystrophic calcification. With congenital toxoplasmosis and cytomegalovirus infections, these calcifications are usually seen in the basal ganglia and periventricular areas, whereas with herpes simplex infections, the calcifications are located in the thalamic, periventricular and gyral regions [16]. The dense calcifications seen in patients with
Fig. 8 An 8-year-old male with a long complicated medical history was found to have hard-to-miss calcifications on the plain skull $\mathrm{x}$ ray $(\mathbf{a}, \mathbf{d})$. The NCECT $(\mathbf{b}, \mathbf{e})$ and $3 \mathrm{D}$ reconstructions $(\mathbf{c}, \mathbf{f})$ show a large amorphous calcification originating from the basal ganglia, extending into the right lateral ventricle of the patient diagnosed with tuberous sclerosis. Subependymal nodules associated with tuberous sclerosis can calcify with age, typically presenting with globular or sometimes ring-like calcification
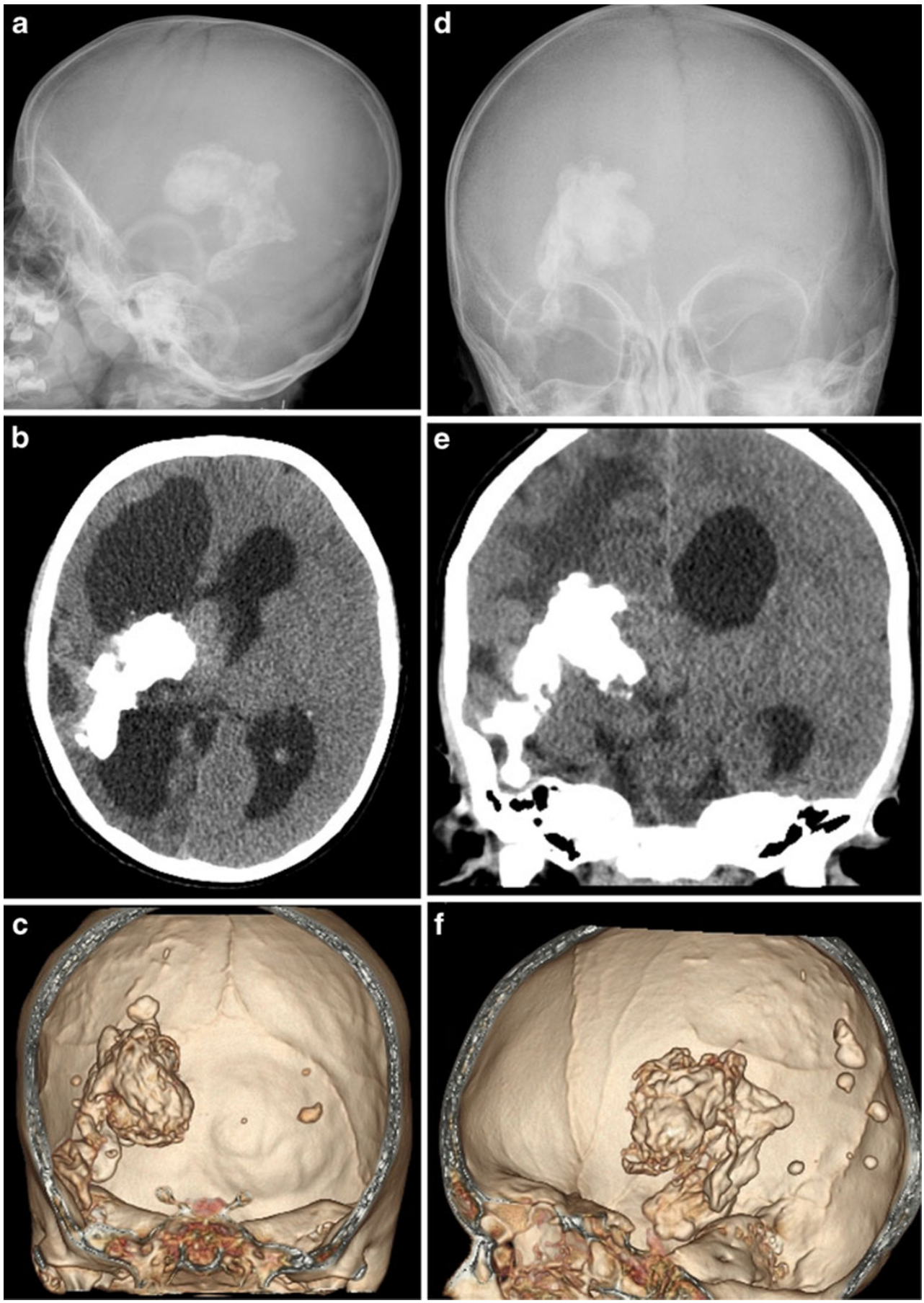
congenital toxoplasmosis can also have a random distribution, with lesion sizes that correlate with the duration of infection. Interestingly, treatment can result in shrinkage and even resolution of these calcifications (Fig. 7) [18, 40, 43]. Congenital rubella infections usually result in calcifications in the basal ganglia, periventricular regions and brainstem. Congenital herpes infection can lead to chronic encephalitis resulting in extensive encephalomalacia and coarse calcification in the remaining brain parenchyma.

Granulomatous infections such as tuberculosis as well as parasitic infections such as neurocysticercosis and cerebral hydatid cyst disease can also result in characteristic intracranial calcifications. Knowledge of a history of travel to endemic areas together with biochemical tests, clinical data and specific imaging findings can often lead to a confident diagnosis. Tuberculosis can result in intracranial calcification in 10 $20 \%$ of cases and is usually located supratentorially in adults and infratentorially in children. Calcified tuberculomas can range in size from about a centimetre to several centimetres and can appear as a "broken shell" or a dense centrally located lobulated calcification $[6,10,44]$. Neurocysticercosis is the leading cause of adult-onset seizures in less developed countries, as shown by epidemiological studies, with no consensus on whether the intracranial calcifications are epileptogenic or not [45-47]. The calcifications represent dead larvae and have the appearance of a dense calcified cyst that sometimes contains a dense eccentric nodule. Lastly, cerebral hydatid disease is an extremely rare cause of intracranial calcification. The lesions are usually single, septated or multilocular and represent the dead parasite [48-50].

\section{Congenital}

Congenital conditions known to cause intracranial calcifications and brain stones include Sturge-Weber syndrome, tuberous sclerosis as well as lipomas and neurofibromatosis. SturgeWeber syndrome calcifications are usually described as "double contoured curvilinear" or "tram-track", closely approximating the gyral patterns in the parietal and occipital regions. They can be bilateral in $15 \%$ to $20 \%$ of cases $[18,51]$. On the other hand, the calcifications seen in the tubers associated with tuberous sclerosis can resemble the gyral pattern seen in SturgeWeber syndrome (Fig. 8). These calcifications can occur in up to more than $50 \%$ of cases $[52,53]$. Subependymal nodules
Fig. 9 A 35-year-old female with a history of multiple shunt revisions was found to have symmetric calcifications in the cerebellum and basal ganglia on $\mathrm{CT}(\mathbf{a}, \mathbf{b})$ and $3 \mathrm{D}$ reconstruction (c). Although not confirmed in this patient, the presence of symmetric calcifications in these regions in young patients is generally thought to be related to a possible diagnosis of Fahr syndrome or an endocrine disorder
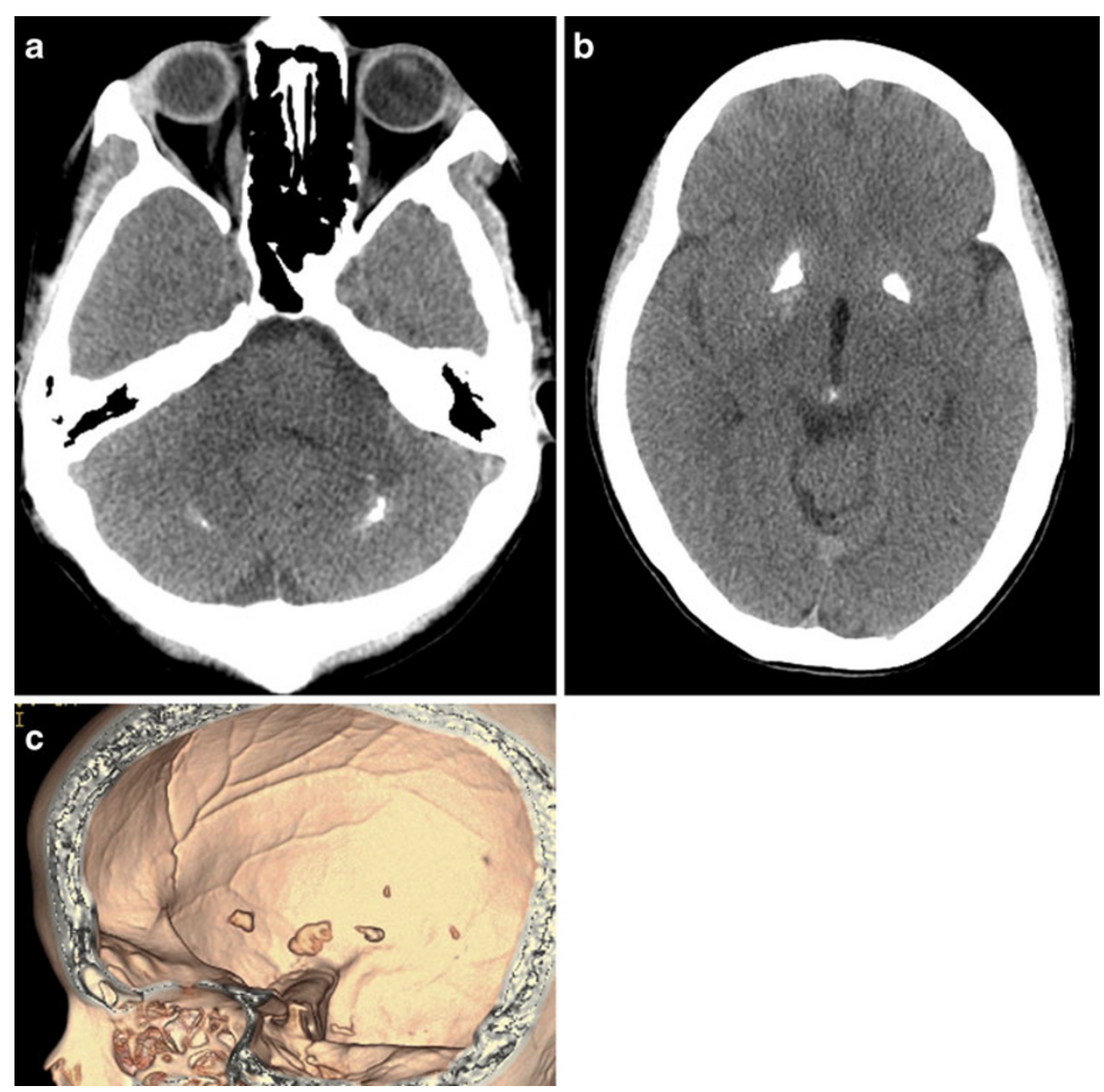
also associated with tuberous sclerosis can calcify with age, often presenting with globular or sometimes ring-like calcification. Neurofibromatosis type 2 can also present with calcifying subependymal nodules, although the calcifying lesions that are more commonly associated with them are the disease-related tumours such as meningiomas or non-tumoral lesions located in the choroid plexus, cerebral hemispheres or cerebellar hemispheres [54]. Lipomas are considered to be rare congenital benign malformations resulting from developmental aberrations involving the meninx primitiva. They are usually located in the midline, in close proximity to the corpus callosum, and are associated with other brain malformations in over $50 \%$ of cases [55, 56]. Lipoma-associated calcifications are often seen particularly in interhemispheric locations as curvilinear along the capsule or as centrally located nodules. Up to half of the lipomas located in the suprasellar or interpeduncular areas are known to ossify. In one series, it was noted that no correlation exists between the presence of calcification and the location of the lipomatous lesions [56].

\section{Endocrine/metabolic}

Intracranial calcifications and brain stones due to endocrine and metabolic causes are generally the result of abnormalities in calcium homeostasis and characteristically symmetrically affect the basal ganglia, thalamus and cerebellum. Fahr's syndrome is an exception in that there are usually no accompanying abnormalities involving serum calcium levels or hormone levels. The basal ganglia, white matter and cerebellar calcifications in Fahr's syndrome may be minimal or massive, and have been demonstrated in pathological studies to be calcium deposits in capillary walls, small arterioles and veins including perivascular spaces, with studies showing a correlation between the amount of calcification and symptom severity (Fig. 9) [14, 57]. On the other hand, diabetes mellitus has also been shown to result in bilateral calcifications in the basal ganglia and gray-white matter interfaces presumably due to hypernatremia-induced endothelial cell damage with a relative lack of neurological symptoms [58]. Hypoparathyroidism, pseudohypoparathyroidism and hyperparathyroidism affect calcium homeostasis because of parathyroid gland dysfunction and abnormal parathyroid hormone levels, resulting in calcifications in the basal ganglia, dentate nucleus and subcortical areas with clinical symptoms ranging from seizures to tremors and parkinsonism [59]. Calcium chelation using bisphosphonates is currently being investigated as possible treatment for symmetric calcification-related neurological symptoms with promising initial results [57, 60].

\section{Conclusion}

Brain stones are more common than previously thought. Modern imaging modalities allow their identification in a wide range of clinical entities. Computed tomography is the mainstay in identifying and characterising brain stones while certain MRI sequences (gradient echo T2* and susceptibilityweighted imaging) are considered adjunctive. Brain stones may be extra- or intra-axial in location. Extra-axial brain stones comprise tumours and exaggerated physiological calcifications. Intra-axial calcifications can be classified under neoplastic, vascular, infectious, congenital and endocrine/ metabolic aetiologies. Imaging findings combined with essential clinical information can help in narrowing the differential diagnosis, determining disease state or evaluating effect of therapy.

The authors declare no conflicts of interest. No funding was received for this work.

\section{Conflict of interest None}

Open Access This article is distributed under the terms of the Creative Commons Attribution License which permits any use, distribution, and reproduction in any medium, provided the original author(s) and the source are credited.

\section{References}

1. Tiberin P, Beller A (1963) Observations on so-called brain stones or cerebral calculi. Neurology 13:464-464

2. Shafey S, Gargano F, Mackey E (1966) Angiomatous malformation as a cause of cerebral calculus. Case report. J Neurosurg 24:898-900

3. Martin F Jr, Lemmen L (1952) Calcification in intracranial neoplasms. Am J Pathol 28:1107-1131

4. Go JL, Zee CS (1998) Unique CT imaging advantages. Hemorrhage and calcification. Neuroimaging Clin N Am 8:541-558

5. Kalan C, Burrows EH (1962) Calcification in intracranial gliomata. Brit J Radiol 35:589-602

6. Watts J, Singh J, Schoppe C, Johnson A (2012) Calcified intracranial masses. Clin Neuroradiol 22:253-256

7. Basak RC (2009) A case report of basal ganglia calcification-a rare finding of hypoparathyroidism. Oman Med J 24:220-222

8. Kiroglu Y, Çalli C, Karabulut N, Öncel Ç (2010) Intracranial calcifications on CT. Diagn Interv Radiol 16:263-269

9. Kieffer SA, Gold L (1974) Intracranial physiologic calcifications, in: Semin Roentgenol: pp. 151-162

10. Wasay M, Kheleani BA, Moolani MK, Zaheer J, Pui M, Hasan S, Muzaffar S, Bakshi R, Sarawari AR (2003) Brain CT and MRI findings in 100 consecutive patients with intracranial tuberculoma. J Neuroimaging 13:240-247

11. Tsuruda J, Bradley W (1987) MR detection of intracranial calcification: a phantom study. Am J Neuroradiol 8:1049-1055

12. Wu Z, Mittal S, Kish K, Yu Y, Hu J, Haacke EM (2008) Identification of calcification with MRI using susceptibility-weighted imaging: a case study. J Magn Reson Imaging 29:177-182

13. Holland B, Kucharczyk W, Brant-Zawadzki M, Norman D, Haas D, Harper P (1985) MR imaging of calcified intracranial lesions. Radiology 157:353-356

14. Avrahami E, Cohn D-F, Feibel M, Tadmor R (1994) MRI demonstration and CT correlation of the brain in patients with idiopathic intracerebral calcification. J Neurol 241:381-384 
15. Bühring U, Herrlinger U, Krings T, Thiex R, Weller M, Küker W (2001) MRI features of primary central nervous system lymphomas at presentation. Neurology 57:393-396

16. Nickerson JP, Richner B, Santy K, Lequin MH, Poretti A, Filippi CG, Huisman TA (2012) Neuroimaging of pediatric intracranial infection - part 2: TORCH, viral, fungal, and parasitic infections. J Neuroimaging 22:e52-e63

17. Parizel P, van den Hauwe L, DeBelder F, VanGoethem J, Venstermans C, Salgado R, Voormoolen M, Hecke WV (2010) Magnetic resonance imaging of the brain. Springer, Berlin

18. Makariou E, Patsalides AD (2009) Intracranial calcifications. Appl Radiol 38:48-50

19. Picht T, Stendel R, Stoltenburg-Didinger G, Brock M (2004) Giant intracerebral choroid plexus calcification. Acta Neurochir 146:12591261

20. Parizel PM, Carpentier K, Van Marck V, Venstermans C, De Belder F, Van Goethem J, van den Hauwe L, Menovsky T (2012) Pneumosinus dilatans in anterior skull base meningiomas. Neuroradiology 55:307311

21. Eshed V, Latimer B, Greenwald CM, Jellema LM, Rothschild BM, Wish-Baratz S, Hershkovitz I (2002) Button osteoma: its etiology and pathophysiology. Am J Phys Anthropol 118:217-230

22. Lui ST, Lee TN (1997) Intracerebral osteoma: case report. Br J Neurosurg 11:250-252

23. Cakirer S, Karaarslan E, Arslan A (2003) Spontaneously T1hyperintense lesions of the brain on MRI: a pictorial review. Curr Probl Diagn Radiol 32:194-217

24. Ghosal N, Thakre D, Murthy G, Hegde A (2007) Cerebral calculi in the temporal horn of the lateral ventricle: report of an unusual case. Histopathology 50:817-818

25. Aiken A, Akgun H, Tihan T, Barbaro N, Glastonbury C (2009) Calcifying pseudoneoplasms of the neuraxis: CT, MR imaging, and histologic features. Am J Neuroradiol 30:1256-1260

26. Nonaka Y, Aliabadi HR, Friedman AH, Odere FG, Fukushima T (2012) Calcifying pseudoneoplasms of the skull base presenting with cranial neuropathies: case report and literature review. J Neurol Surg Rep 73:041-047

27. Daghighi M, Rezaei V, Zarrintan S, Pourfathi H (2007) Intracranial physiological calcifications in adults on computed tomography in Tabriz, Iran. Folia Morphol 66:115-114

28. Debnath J, Satija L, George RA, Vaidya A, Sen D (2009) Computed tomographic demonstration of unusual ossification of the falx cerebri: a case report. Surg Radiol Anat 31:211-213

29. Halstead AE, Christopher F (1923) Calcification and ossification of the meninges. Arch Surg 6:847-857

30. Tubbs RS, Kelly DR, Lott R, Salter EG, Oakes WJ (2006) Complete ossification of the human falx cerebri. Clin Anat 19:147-150

31. Lee D, Larson T 3rd, Norman D et al (1988) Falx ossification-MR visualization. Can Assoc Radiol J 39:260-262

32. Sands SF, Farmer P, Alvarez O, Keller IA, Gorey MT, Hyman RA (1987) Fat within the falx: MR demonstration of falcine bony metaplasia with marrow formation. J Comput Assist Tomogr 11:602-605

33. Rao SR, Rao TR, Ovchinnikov N, McRAE A, Rao AVC (2007) Unusual isolated ossification of falx cerebri: a case report. Neuroanatomy 6:54-55

34. Kasantikul V, Wirt TC, Allen VA, Netsky MG (1980) Identification of a brain stone as calcified hemangioma. J Neurosurg 52:862-866

35. Trump BF, Berezesky IK, Sato T, Laiho KU, Phelps PC, DeClaris N (1984) Cell calcium, cell injury and cell death. Environ Health Perspect 57:281-287

36. Packer RJ, Cogen P, Vezina G, Rorke LB (1999) Medulloblastoma: clinical and biologic aspects. Neuro-oncology 1:232-250

37. Drevelegas A (2011) Imaging of brain tumors with histological correlations. Springer, Berlin
38. Atlas SW (2008) Magnetic resonance imaging of the brain and spine. Lippincott Williams \& Wilkins, Philadelphia

39. Knaut M, Cognard C, D rfler A, Forsting M, Küker W, Pierot L, Spelle L, Szikora I, Wanke I et al (2008) Intracranial vascular malformations and aneurysms: from diagnostic work-up to endovascular therapy. Springer, Berlin

40. Osborn AG, Salzman KL, Barkovich AJ (2004) Others diagnostic imaging: brain. Amirsys, Salt Lake City

41. Matsumoto R, Shintaku M, Suzuki S, Kato T (1998) Cerebral perivenous calcification in neuropsychiatric lupus erythematosus: a case report. Neuroradiology 40:583-586

42. Pinto RS, Kricheff II, Butler AR, Murali R (1979) Correlation of computed tomographic, angiographic, and neuropathological changes in giant cerebral aneurysms. Radiology 132:85-92

43. Patel DV, Holfels EM, Vogel NP, Boyer KM, Mets MB, Swisher CN, Roizen N, Stein LK, Stein MA et al (1996) Resolution of intracranial calcifications in infants with treated congenital toxoplasmosis. Radiology 199:433-440

44. Selekler K, Erbengi A, Saribas O, Önol B (1983) Giant calcified and ossified midbrain tuberculoma. J Neurosurg 58:133-135

45. da Gama CN, Kobayashi E, Li LM, Cendes F (2005) Hippocampal atrophy and neurocysticercosis calcifications. Seizure 14:85-88

46. Velasco T, Zanello P, Dalmagro C, Araújo D Jr, Santos A, Bianchin M, Alexandre V Jr, Walz R, Assirati J et al (2006) Calcified cysticercotic lesions and intractable epilepsy: a cross sectional study of 512 patients. J Neurol Neurosurg Psychiatry 77:485-488

47. Raina SK, Razdan S, Pandita K, Sharma R, Gupta V, Razdan S (2012) Active epilepsy as indicator of neurocysticercosis in Rural Northwest India. Epilepsy Res Treat

48. Senturk S, Oguz K, Soylemezoglu F, Inci S (2006) Cerebral alveolar echinoccosis mimicking primary brain tumor. Am J Neuroradiol $27: 420-422$

49. Bükte Y, Kemaloglu S, Nazaroglu H, Ozkan U, Ceviz A, Simsek M et al (2004) Cerebral hydatid disease: CT and MR imaging findings. Swiss Med Wkly 134:459-467

50. Ersahin Y, Mutluer S, Güzelbag E (1993) Intracranial hydatid cysts in children. Neurosurgery 33:220-223

51. Boltshauser E, Wilson J, Hoare R (1976) Sturge-Weber syndrome with bilateral intracranial calcification. J Neurol Neurosurg Psychiatry 39:429-435

52. Inoue $\mathrm{Y}$, Nemoto $\mathrm{Y}$, Murata R, Tashiro T, Shakudo M, Kohno K, Matsuoka O, Mochizuki K (1998) CT and MR imaging of cerebral tuberous sclerosis. Brain Dev 20:209-221

53. Yakovlev PI, Corwin W (1939) A roentgenographic sign in cases of tuberous sclerosis of brain (multiple "brain stones"). Arch Neurol Psychiatry 42:1030-1037

54. Mayfrank L, Mohadjer M, Wullich B (1990) Intracranial calcified deposits in neurofibromatosis type 2. Neuroradiology 32:33-37

55. Jabot G, Stoquart-Elsankari S, Saliou G, Toussaint P, Deramond H, Lehmann P (2009) Intracranial lipomas: clinical appearances on neuroimaging and clinical significance. J Neurol 256:851-855

56. Yildiz H, Hakyemez B, Koroglu M, Yesildag A, Baykal B (2006) Intracranial lipomas: importance of localization. Neuroradiology 48:1-7

57. Manyam BV (2005) What is and what is not "Fahr"s disease'. Parkinsonism Relat Disord 11:73-80

58. Al-Kandari SR, Pandey T, Badawi MH (2008) Intracranial calcification in central diabetes insipidus. Pediatr Radiol 38:101-103

59. Manabe Y, Araki M, Takeda K, Yokota S, Kimura T (1989) Pseudohypoparathyroidism with striopallidodentate calcification - a case report and review of the literature. Jpn J Med 28:391-395

60. Loeb JA, Sohrab SA, Huq M, Fuerst DR (2006) Brain calcifications induce neurological dysfunction that can be reversed by a bone drug. J Neurol Sci 243:77-81 